\title{
Transcatheter aortic valve replacement in patients with severe aortic stenosis who are at high risk for surgical complications: Summary assessment of the California Technology Assessment Forum
}

\author{
Jeffrey A. Tice, MD, ${ }^{a}$ Frank W. Sellke, MD, ${ }^{b}$ and Hartzell V. Schaff, MD $^{c}$
}

\begin{abstract}
Background: The California Technology Assessment Forum is dedicated to assessment and public reporting of syntheses of available data on medical technologies. In this assessment, transcatheter aortic valve replacement (TAVR) was evaluated for patients with severe aortic stenosis (AS) who are at high risk for complications.
\end{abstract}

\begin{abstract}
Methods and Results: In this assessment, 5 criteria were used: Regulatory approval, sufficient scientific evidence to allow conclusions on effectiveness, evidence that the technology improves net health outcomes, evidence that the technology is as beneficial as established methods, and availability of the technology outside investigational settings. In this assessment, all 5 criteria were judged to have been met. The primary benefit of TAVR is the ability to treat AS in patients who would otherwise be ineligible for surgical aortic valve replacement. It may also be useful for patients at high surgical risk by potentially reducing periprocedural complications and avoiding the morbidity and recovery from undergoing heart surgery. Potential harms include the need for conversion to an open procedure, perioperative death, myocardial infarction, stroke, bleeding, valve embolization, aortic regurgitation, heart block that requires a permanent pacemaker, renal failure, pulmonary failure, and major vascular complications such as cardiac perforation or arterial dissection. Potential long-term harms include death, stroke, valve failure or clotting, and endocarditis. As highlighted at the February 2012 California Technology Assessment Forum meeting, the dispersion of this technology to new centers across the United States must proceed with careful thought given to training and proctoring multidisciplinary teams to become new centers of excellence.

Conclusions: TAVR is a potentially lifesaving procedure that may improve quality of life for patients at high risk for surgical AVR. However, attention needs to be paid to appropriate patient selection, their preoperative evaluation, surgical techniques, and postoperative care to preserve and improve on the results attained in the Placement of Aortic Transcatheter Valve trial. Specialty societies are collaborating to ensure that this happens in a rational and comprehensive manner. (J Thorac Cardiovasc Surg 2014;148:482-91)
\end{abstract}

\section{Supplemental material is available online.}

The California Technology Assessment Forum (CTAF) is dedicated to assessment and public reporting of syntheses of available data on medical technologies. Reports are used by health plans, providers, and patients to guide health care decisions and inform health policy initiatives. The CTAF is managed by Blue Shield of California Foundation (BSCF),

From Division of General Internal Medicine, ${ }^{\mathrm{a}}$ Department of Medicine University of California San Francisco, San Francisco, Calif; Division of Cardiothoracic Surgery, ${ }^{\mathrm{b}}$ Department of Surgery, Brown Medical School and Rhode Island Hospital, Providence, RI; and Division of Cardiovascular Surgery, ${ }^{\mathrm{c}}$ Department of Surgery, Mayo Clinic, Rochester, Minn.

Disclosures: Dr Selke is on the advisory board for Ikaria, Medicines Company, and Revo Pharmaceutical and is on the adjudication committee for CSL Behring. All other authors have nothing to disclose with regard to commercial support.

Received for publication July 11, 2013; revisions received Sept 11, 2013; accepted for publication Sept 23, 2013; available ahead of print Nov 18, 2013.

Address for reprints: Frank W. Sellke, MD, Division of Cardiothoracic Surgery, Brown University Medical School, 2 Dudley St, MOC 360, Providence, RI 02905 (E-mail: fsellke@lifespan.org).

$0022-5223 / \$ 36.00$

Copyright (C) 2014 by The American Association for Thoracic Surgery

http://dx.doi.org/10.1016/j.jtcvs.2013.09.056 which is a separate nonprofit organization that receives funding from the Blue Shield of California health plan, but is governed by its own board of trustees. CTAF and BSCF are not revenue-generating organizations or consultant organizations; they do not endorse specific technologies, advocacy organizations, or organizations that determine health plan benefit coverage. CTAF technology assessments are available at http://www.ctaf.org.

The assessment process involves a thorough literature review and determination of comparative effectiveness and value of different care options. In the assessment of transcatheter aortic valve replacement (TAVR) for patients with severe aortic stenosis (AS) who are at high risk for complications, 5 criteria were used: regulatory approval, sufficient scientific evidence to allow conclusions on effectiveness, evidence that the technology improves net health outcomes, evidence that the technology is as beneficial as established methods, and availability of the technology outside investigational settings.

Drafts of technology assessments are posted for public comment and reviewed at an open forum where input is taken from consumers, payors, industry representatives, and relevant health care provider organizations. The American Association of Thoracic Surgery (AATS) has 


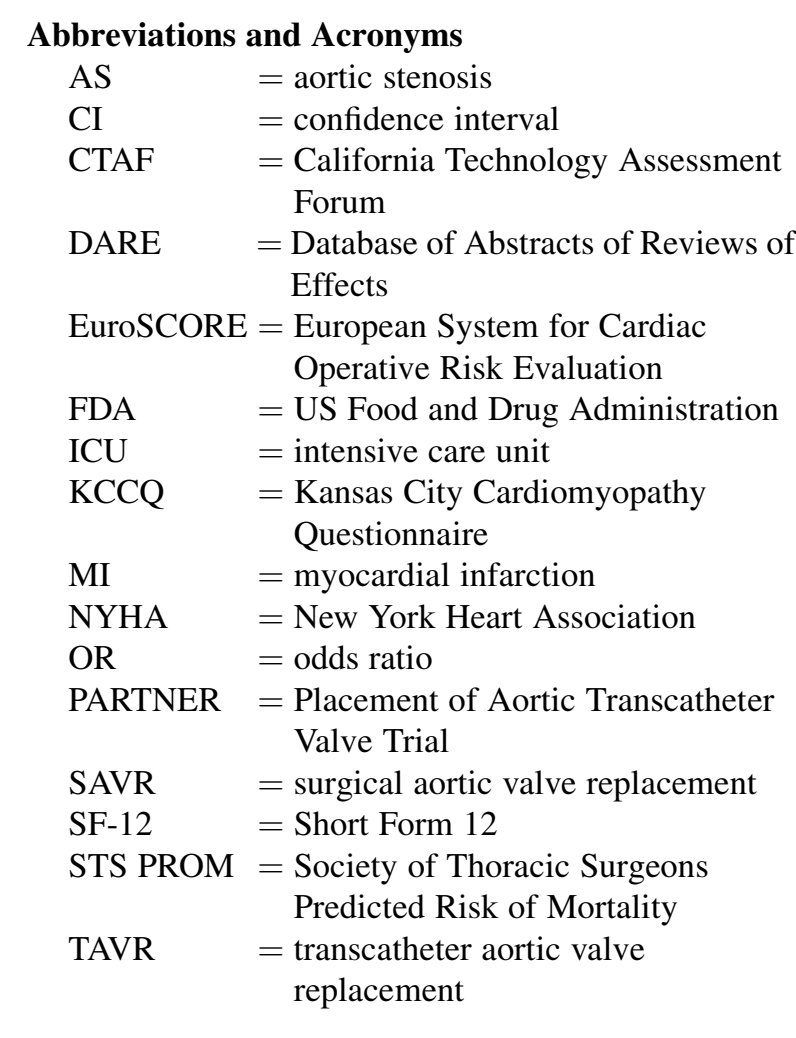

been an active participant in the reviews relevant to our specialty, and the following technology assessment of TAVR was approved by the AATS representative, Dr Frank Sellke, as well as the AATS Council.

The primary benefit of TAVR is the ability to treat AS in patients who would otherwise be ineligible for surgical aortic valve replacement (SAVR). It may also be useful for patients at high surgical risk by potentially reducing periprocedural complications and avoiding the morbidity and recovery from undergoing heart surgery. Potential harms include the need for conversion to an open procedure, perioperative death, myocardial infarction (MI), stroke, bleeding, valve embolization, aortic regurgitation, heart block that requires a permanent pacemaker, renal failure, pulmonary failure, and major vascular complications such as cardiac perforation or arterial dissection. Potential long-term harms include death, stroke, valve failure or clotting, and endocarditis. The focus of this statement is a high-risk cohort of patients with AS, rather than inoperable patients.

\section{TECHNOLOGY ASSESSMENT}

Technology Assessment Criterion 1: The Technology Must Have Final Approval From the Appropriate Government Regulatory Bodies

On November 2, 2011, the SAPIEN Transcatheter Heart Valve model 9000TFX (Edwards Lifesciences, Irvine,
Calif), sizes $23 \mathrm{~mm}$ and $26 \mathrm{~mm}$, received US Food and Drug Administration (FDA) premarket approval for transfemoral delivery in patients with severe, symptomatic, native, aortic valve stenosis who have been determined to be inoperable by a cardiac surgeon. On October 19, 2012, the SAPIEN Transcatheter Heart Valve model 9000TFX, sizes $23 \mathrm{~mm}$ and $26 \mathrm{~mm}$, received FDA premarket approval for transfemoral and transapical delivery in patients with severe, symptomatic, native, aortic valve stenosis who have been determined to be at high risk defined as a Society of Thoracic Surgeons predicted operative risk score of $8 \%$ or higher or are judged by the heart team to be at $15 \%$ or higher risk of operative mortality.

The Edwards SAPIEN Transcatheter Heart Valve, model 9000TFX is the only product approved by the FDA at this time. Edwards will continue to monitor and evaluate the SAPIEN valve and TAVR as a procedure via the national Transcatheter Valve Therapy Registry. Thus, Technology Assessment (TA) Criterion 1 was met. It should be understood that other valves are in clinical trials and in development, but only the SAPIEN valve has, to date, been approved for use in the United States. However, we take the liberty of considering TAVR in a more general sense.

\section{TA Criterion 2: The Scientific Evidence Must Permit Conclusions Concerning the Effectiveness of the Technology Regarding Health Outcomes}

The MEDLINE database, EMBASE, Cochrane clinical trials database, Cochrane reviews database, and the Database of Abstracts of Reviews of Effects (DARE) were searched using the key words "transcatheter aortic valve replacement" OR "transcatheter aortic valve implantation" OR "percutaneous aortic valve replacement" OR "CoreValve" OR "Sapien." The search was performed for the period from 1945 to January 2012. References were also solicited from the manufacturers and local experts. The abstracts of citations were reviewed for relevance and all potentially relevant articles were reviewed in full. Case series describing at least 100 patients treated with TAVR, comparative studies with surgical therapy, and randomized trials comparing TAVR with medical therapy were included.

The search identified 1356 potentially relevant studies (Figure E1). After elimination of duplicate and nonrelevant references, including reviews and animal studies, the search identified 45 articles describing 16 case series, ${ }^{1-27}$ 10 comparative trials, ${ }^{28-37}$ and 1 randomized trial. ${ }^{38-42}$ An additional 69 early case series and 1 comparative study were excluded because they were too small to provide reliable estimates of the outcomes of interest. ${ }^{15,18,20,43-107}$ Two of the publications included with the case series ${ }^{6,7}$ and 1 of the publications included with the comparative studies $^{33}$ were meta-analyses of previous literature 
including many of the smaller studies not otherwise described in this assessment. Thus, TA Criterion 2 was met.

\section{TA Criterion 3: The Technology Must Improve Net Health Outcomes}

Symptomatic AS has a high short-term mortality so total mortality should be the primary outcome of interest. Treatment of AS is associated with an increased risk for stroke and some patients perceive that their quality of life living with the disabilities of a stroke could be worse than death, so stroke risk is a key outcome. Quality of life and functional status are also major concerns. The New York Heart Association (NYHA) developed the system that is most commonly used to quantify the degree of functional limitation imposed by heart disease. ${ }^{108}$ Two more detailed quality of life questionnaires, the Kansas City Cardiomyopathy Questionnaire (KCCQ) and the Medical Outcomes Study Short Form 12 (SF-12) were used in some of the studies. The KCCQ is a validated 23-item questionnaire focusing on 5 domains: symptoms, physical limitation, social limitation, self-efficacy, and quality of life. ${ }^{109,110}$ Other important periprocedural and longer-term outcomes include MI, major bleeding, kidney injury, major vascular complications, and valve dysfunction including aortic regurgitation. A consensus panel published clear definitions for these outcomes in 2011. ${ }^{111}$ Table E1 describes when and where the studies were performed, which valve type was used, and a brief summary of the characteristics of the patients in the studies.

The procedural success rate was generally high, ranging from $95 \%$ to $99 \%$ in the most recent series. Table E2 summarizes the procedural outcomes and events over 30 days. The most important outcome, 30-day mortality, varied from $6 \%$ to $19 \%$, likely due to differences in the underlying risk of the different patient groups studied. The risk of major stroke varied from $1 \%$ to $5 \%$. TAVR is known to cause some arrhythmias and $2 \%$ and $39 \%$ of patients in these case series required insertion of a permanent pacemaker. Case series that evaluated both the CoreValve (Medtronic, Minneapolis, Minn) and the SAPIEN valve suggested that the requirement for a pacemaker is more common with the CoreValve. ${ }^{14,18,25}$ Major vascular complications varied widely ( $2 \%$ to $28 \%)$, in part because of differences in what was classified as a vascular complication. Aortic regurgitation, both around and through the implanted valve, is a common complication but most are trivial to mild and unlikely to cause symptoms. However, the prevalence of moderate to severe aortic regurgitation has been reported to be between $2 \%$ and $26 \%$ in these case series. The rates of MIs, valve embolization, and cardiac tamponade were generally low $(<1 \%)$. The need for repeat interventions on the implanted valve was between $1 \%$ and $3 \%$, but these data were not consistently reported. ${ }^{12,25}$ Table E3 summarizes the outcomes at 1 year including quality of life outcomes.

Gilard and colleagues ${ }^{5}$ published data from the largest prospective cohort study of TAVR in 2012. The French Aortic National CoreValve and Edwards (FRANCE 2) Registry collected data on 3195 patients treated between January 2010 and October 2011. The average age of the patients was 83 years and half were women. The treating physicians used the SAPIEN valve for $67 \%$ of patients and the CoreValve for the remaining $33 \%$. They used the transfemoral approach for $75 \%$ of patients and the transapical approach for $18 \%$. The PARTNER randomized trials, as well as observational studies, identified stroke, paravalvular aortic regurgitation, and the need for permanent pacemaker placement as important harms associated with TAVR. ${ }^{112}$ These outcomes were emphasized in this FRANCE 2 Registry publication. ${ }^{5}$ After 1 year of follow-up in the FRANCE 2 Registry, the incidence of stroke was $4.1 \%$. After 30 days, new pacemakers were placed in $16 \%$ of patients and paravalvular leaks were observed in $64 \%$ of patients, although only $16 \%$ were moderate or severe. New pacemaker placement was more common with the CoreValve than the SAPIEN device ( $24 \%$ vs $12 \%)$. Mortality was lower with the transfemoral approach than the transapical approach at 30 days $(8.5 \%$ vs $14 \%)$ and at 1 year $(17 \%$ vs $22 \%)$. In a multivariable analysis adjusting for baseline risk factors, factors associated with an increased mortality at 1 year included, as expected, both a higher logistic EuroSCORE (European System for Cardiac Operative Risk Evaluation) and a higher NYHA functional class, as well as the transapical approach and moderate to severe paravalvular regurgitation. This supports the hypothesis that the transfemoral approach should be the preferred approach if it is technically feasible, and that advances in valve design and delivery that reduce the incidence of paravalvular regurgitation may reduce mortality at 1 year and beyond.

Comparative studies with SAVR. Ten studies compared the outcomes in high-risk patients with symptomatic AS referred for TAVR with patients who were treated with SAVR. ${ }^{28-37}$ The patient characteristics and the primary outcomes of the studies are summarized in Tables E1 to E3. Most of these studies were retrospective. The investigators used a variety of approaches to attempt to account for baseline differences between patients treated with TAVR and those treated with SAVR $(n=1008)$ including matching, multivariable regression, and propensity score techniques both for adjustment and matching. The results of the earliest study by Piazza and colleagues $^{34}$ are instructive. Patients in the TAVR group $(\mathrm{n}=114)$ were significantly older, had higher NYHA class, and were at much higher operative risk according to the logistic EuroSCORE than those in the SAVR group $(\mathrm{n}=1008)$. As would be expected based on those differences, the 30-day mortality was substantially higher 
in the TAVR group $(9.6 \%$ vs $2.3 \%$; odds ratio [OR], 4.6 ; $95 \%$ confidence interval $[\mathrm{CI}], 2.2-9.6)$. Using different logistic regression models to control for confounding gave a range for results from 1 analysis suggesting that TAVR may be superior to SAVR (adjusted OR, 0.60; 95\% CI, 0.11-3.36) to another suggesting that outcomes with TAVR may be much worse (adjusted OR, 7.6; 95\% CI, $0.9-63$ ). Using propensity scores, the models ranged from an adjusted OR of 0.35 (95\% CI, 0.04-2.7) to an adjusted OR of 3.2 (95\% CI, 0.3-32). All the confidence intervals included 1 but the confidence intervals were wide and the adjusted ORs varied widely by the choice of modeling technique. This highlights the difficulty in appropriately and fully adjusting for confounding in observational studies like this and demonstrates why it was appropriate to require randomized trials to evaluate the relative benefits and harms of TAVR both for inoperable and high-risk patients.

Jilaihawi and colleagues ${ }^{33}$ published a meta-analysis comparing outcomes in 5025 high-risk patients with severe AS treated with TAVR (16 studies) to those of 3512 patients treated with SAVR (19 studies). Although the number of patients is impressive, the investigators simply pooled the data from these disparate studies without appropriate meta-analytical techniques. Undoubtedly, there was significant heterogeneity between the studies that were pooled as was described in the meta-analysis by Genereux and colleagues. ${ }^{6}$ Furthermore, patients from the 2 groups most often were not treated at the same institution or even in the same country. It is difficult to draw any meaningful conclusions from this study.

Four of the studies ${ }^{30-32,36}$ used propensity scores to match patients treated with SAVR with those treated with TAVR and 1 matched on baseline characteristics ${ }^{35}$ (age, logistic EuroSCORE, coronary artery disease, valvular heart disease). In general, these studies found that patients in the TAVR group had shorter procedural times, spent fewer days in the intensive care unit, and had shorter hospital stays. There were no significant differences in 30-day mortality and stroke rates. Patients in the TAVR group required permanent pacemakers more often and had a higher incidence of paravalvular aortic regurgitation.

Randomized clinical trials. The Placement of Aortic Transcatheter Valve Trial. The PARTNER (Placement of Aortic Transcatheter Valve Trial) ${ }^{113}$ included 2 parallel, randomized clinical trials, 1 in operable, high-risk

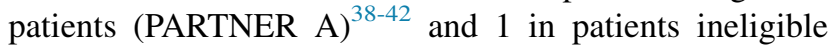
for surgery (PARTNER B). ${ }^{113-115}$ This technology assessment focuses on the PARTNER A trial because our February 2012 CTAF assessment ${ }^{112}$ focused on the PARTNER B trial and the use of TAVR for patients ineligible for SAVR.

Patients were considered at high risk for operative complications or death if they had a predicted probability of death within 30 days of surgery of at least $15 \%$ as determined by surgeons at each center. ${ }^{42}$ A Society of Thoracic Surgeons (STS) predicted risk of mortality (PROM) score of at least $10 \%$ was used as a guideline for high risk. Patients were required to have severe AS defined by either an aortic valve area of less than $0.8 \mathrm{~cm}^{2}$, an aortic valve gradient of at least $40 \mathrm{~mm} \mathrm{Hg}$, or a peak aortic jet velocity of at least $4.0 \mathrm{~m} / \mathrm{s}$. They also were required to have NYHA class II, III, or IV symptoms. Patients were excluded if they had a bicuspid or noncalcified aortic valve, acute MI, coronary artery disease requiring revascularization, left ventricular ejection fraction less than $20 \%$, severe mitral or aortic regurgitation, transient ischemic attack or stroke in the previous 6 months, or severe renal insufficiency (creatinine $>3.0 \mathrm{mg} / \mathrm{dL}$ or preoperative renal replacement). Eligible patients were randomized to receive the Edwards SAPIEN heart valve system (transfemoral or transapical) or SAVR. The primary end point of the trial was death from any cause.

The study characteristics and findings are summarized in Tables E1 to E3. In brief, 348 patients were randomized to the TAVR group and 351 to the SAVR group. Follow-up was $100 \%$ complete over 2 years and the primary analysis was done according to strict intention-to-treat principles. No blinding was reported and no sham procedure was performed.

The average age of the participants was 84 years and $43 \%$ were female. Their predicted operative mortality by the logistic EuroSCORE was $28 \%$ and by the STS PROM score was $12 \%$. There were no significant differences between the 2 groups on 26 potential confounders at baseline although there was a trend towards more patients with an increased creatinine level in the TAVR group (11\% vs $7 \%, P=.06)$. An increased creatinine level has been associated with higher mortality in observational studies of aortic valve replacement so this difference would tend to bias results against TAVR.

TAVR was successful for $95 \%$ of patients in the TAVR group. Three patients died during the procedure and it was aborted or converted to open surgery in 16 patients $(4.6 \%)$. More than 1 transcatheter valve was implanted in 7 patients. The reasons for the use of multiple valves included valve embolization (2 patients) and residual aortic regurgitation ( 5 patients). Three of these 7 patients died. Valve embolization occurred in 7 additional patients. The procedure was aborted in 2 patients and converted to an open procedure in the remaining 7 . As expected, the procedure time was shorter for TAVR (133 minutes vs 230 minutes, $P$ values not reported) as was the average stay in the intensive care unit (ICU) after the procedure ( 3 days vs 5 days, $P$ values not reported) and the length of the initial hospitalization ( 8 days vs 12 days, $P$ values not reported).

At 30 days, there were no differences in death from any cause $(3.4 \%$ vs $6.5 \%, P=.07)$, major strokes $(3.8 \%$ vs 
$2.1 \%, P=.20)$, or the combination of the two $(6.9 \%$ vs $8.2 \%, P=.52)$. The TAVR group did have more neurologic events including transient ischemic attacks and minor strokes $(5.5 \%$ vs $2.4 \%, P=.04)$. The TAVR group had more major vascular complications defined as aortic dissection, left ventricular perforation, embolization resulting in permanent damage, vascular injury requiring surgical intervention or causing death, permanent disability, or blood transfusion of at least 3 units $(11.0 \%$ vs $3.2 \%$, $P<.001)$. However, the TAVR group had fewer major bleeding episodes defined as bleeding leading to death or prolonged hospitalization requiring surgical intervention or blood transfusions of at least 3 units $(9.3 \%$ vs $19.5 \%$, $P<.001)$. The TAVR group also had fewer episodes of new onset atrial fibrillation $(8.6 \%$ vs $16.0 \%, P=.006)$. There were no differences in the rate of MIs, new pacemakers, or the need for dialysis. The prevalence of paravalvular aortic regurgitation was more common after TAVR for both minimal disease $(65 \%$ vs $25 \%, P<.001)$ and moderate to severe regurgitation $(12.1 \%$ vs $0.9 \%$, $P<.001)$. More patients in the TAVR group reported NYHA class II or lower symptoms at 30 days $(\sim 72 \%$ vs $\sim 59 \%, P<.001) .{ }^{42}$

At 1 year the outcomes were similar. There were no differences in death from any cause $(24.2 \%$ vs $26.8 \%$, $P=.44)$, major strokes $(5.1 \%$ vs $2.4 \%, P=.07)$, or the combination of the two $(26.5 \%$ vs $28.0 \%, P=.68)$. The difference in mortality at 1 year between the 2 groups $(-2.6 \%, 95 \%$ CI,$-9.3 \%$ to $+4.1 \%)$ was within the prespecified noninferiority boundary of $7.5 \%(P=.001$ for noninferiority). The differences in neurologic outcomes, major vascular complications, and major bleeding persisted. The prevalence of paravalvular aortic regurgitations remained more common after TAVR for minimal disease $(60 \%$ vs $20 \%, P<.001)$ and moderate to severe regurgitation $(6.8 \%$ vs $1.9 \%, P<.001)$.

One of the major concerns raised when CTAF considered TAVR for inoperable patients was the lack of longer-term follow-up. The investigators published the 2-year followup for the PARTNER trials in 2012. ${ }^{39,114}$ There were no cases of structural valve deterioration and valve area was preserved as assessed by echocardiography. There continued to be no differences in overall mortality at 2 years $(35.0 \%$ vs $33.9 \%, P=.78)$, as well as no significant differences in the rate of stroke or rehospitalization. The Kaplan-Meier curves did not diverge at all between 2 and 3 years of follow-up suggesting that the result is likely to be similar over at least 3 years.

Quality of life indicators were better in the TAVR group at 1 month but not at 6 or 12 months. ${ }^{41}$ This likely reflects a decrement in quality of life associated with median sternotomy. Quality of life improvements were nearly identical in the 2 groups at 6 and 12 months as measured by the KCCQ, the SF12, the EQ-5D, and their related subscales.
As noted earlier, this was a high-quality randomized trial with remarkable $100 \%$ follow-up of all patients for 2 years. There were no significant baseline differences between the TAVR and SAVR groups and the only borderline difference would be expected to bias the results against the TAVR group. The primary methodological concern centers on the 42 patients who were not treated as randomized. Only $4(1.1 \%)$ were in the TAVR group and $38(10.8 \%)$ were in the SAVR group $(P<.001)$. This could introduce selection bias. To address this, the investigators performed a strict intentionto-treat analysis and reported this as the primary result. They also performed as-treated analyses for all the major outcomes and none of the conclusions were changed. The other concern was that the time from randomization to treatment was longer for the surgical group (10.6 days vs 15.6 days, $P<.001)$. This may explain why there were more pre-procedural deaths in the surgical group (3 vs 10 deaths). At 30 days, there still would be fewer deaths in the transcatheter group (adding 7 additional deaths to that group) but at 1 year there would have been slightly more deaths in the transcatheter group ( $84+7=91$ vs 89 deaths). Thus, it does not seem that accounting for the difference in preprocedure deaths would change the conclusion of the study.

In summary, a high-risk surgical patient with severe AS who was randomized to TAVR had a similar risk of dying over 2 years of follow-up compared with SAVR. The rates of stroke and rehospitalization were also equivalent, although when all neurologic events were counted, there was a slight excess in the TAVR group. Patients in the TAVR group experienced more major vascular events and more paravalvular aortic regurgitation. Patients in the SAVR group experienced more major bleeding and required longer stays in the ICU and hospital after the valve replacement procedure. Quality of life improved more rapidly in the TAVR group, likely related to the need for a median sternotomy in the SAVR group. However, quality of life improvements were comparable in both groups at 6 and 12 months. There are differences in terms of vascular complications, major bleeding, strokes, atrial fibrillation, and aortic regurgitation but they seem to balance each other and do not have an impact on the medium-term outcomes over 2 to 3 years. Some uncertainty remains about the long-term viability of the transcatheter valves so the outcomes of the studies over 5 years of follow-up should be closely monitored. Thus, TA Criterion 3 was met.

\section{TA Criterion 4: The Technology Must Be as Beneficial as Any Established Alternatives}

The established alternative to TAVR for patients with severe AS is SAVR. Because patients with severe AS are generally older and have multiple comorbidities, they are at high risk for complications during and after SAVR, including death.

The randomized PARTNER A trial, described in detail earlier, directly compared TAVR with SAVR. As discussed 
under TA Criterion 3, over 2 years of complete follow-up there were no statistically or clinically significant differences between the 2 groups in death from any cause, repeat hospitalizations, strokes, the combination of death from any cause and repeat hospitalization, or the combination of death from any cause and stroke. ${ }^{39}$ There was an absolute difference of $8 \%$ more patients having major vascular complications with TAVR and an absolute difference of $10 \%$ more patients having major bleeding complications with SAVR. There were no differences between the groups in quality of life after 1 month or in the incidence of MI, new pacemakers, renal failure, endocarditis, or structural valve deterioration. There was an excess of mild and moderate paravalvular aortic regurgitation in the TAVR group at 30 days and 1 year, which has been associated with an increased risk for death in previous studies. The survival curves remained overlapping for years 1 to 3 of follow-up but there still may be longer-term problems that arise either from the valves themselves or from the paravalvular leaks. This should be watched in continued long-term follow-up given that almost two thirds of the patients in both groups were still alive at 2 years. That said, the data are convincing that TAVR is equivalent to SAVR in high-risk patients for all important outcomes over 2 years. However, the longer-term results remain to be established. Indeed, either paravalvular or valvular aortic insufficiency, which are increased in the TAVR group, are associated with diminished long-term survival.

The definition of high risk is an essential part of this conclusion. The FDA indication for the Edwards SAPIEN device uses essentially the same definition as that used in the inclusion criteria for the PARTNER trial: patients should have an STS PROM score of at least 10 or have at least a $15 \%$ risk of death within 30 days as determined by at least 1 surgeon. There are ongoing randomized trials evaluating the relative risks and benefits of TAVR versus SAVR in lower-risk patients. Therefore, TA Criterion 4 was met.

\section{TA Criterion 5: The Improvement Must Be}

\section{Attainable Outside the Investigational Setting}

TAVR is a technically difficult procedure with a steep learning curve. In the Vancouver single center case series, outcomes improved over time. ${ }^{16}$ The investigators compared results in the first 135 patients with the results in the subsequent 135 patients. The overall success rate increased from $93 \%$ to $98 \%$ and the 30-day mortality decreased from $13 \%$ to $6 \%$. There were fewer cases of device embolization, coronary occlusion, stroke, and major vascular injury in the second half of their case series. ${ }^{16}$ Some of the improvement may reflect changes in the design of the valvular implants and their delivery systems. In addition, patients in the second half of the case series were at significantly lower risk for poor outcomes (STS PROM score 8.5 vs $10.5, P<.01$ ). Clearly, care must be taken to ensure adequate training and proctoring of physicians performing TAVR. Thus, although equivalent outcomes in the investigational and noninvestigational setting are likely, subsequent studies and analysis will be required to confirm this.

Consensus recommendations have been made jointly by the American College of Cardiology Foundation and the STS. ${ }^{116}$ In brief, they recommend that programs using TAVR should be performed at a limited number of specialized heart centers with multidisciplinary teams that include at least 1 interventional cardiologist and 1 cardiac surgeon. All personnel should receive appropriate training and credentialing and follow standard protocols set up by expert consensus groups for evidence-based patient selection, procedural details, and complication management. A registry has been established to track appropriate use and patient outcomes. ${ }^{116}$ Outcomes data from the first year of the registry should be published in 2013 with additional data on whether the outcomes achieved in the PARTNER trial can be replicated in clinical practice in the United States. If followed, these recommendations should ensure that appropriate patients are selected and that highly skilled teams perform the procedure. Thus, TA Criterion 5 was met.

\section{CONCLUSIONS}

AS is common in the elderly and when symptoms arise, about half of these patients die within 2 years. SAVR is an effective therapy for AS that can be performed with relatively low morbidity and mortality given the age and comorbidity of most patients with AS. To address the need for additional treatment options for patients with AS who are inoperable or very high risk for surgical treatment, 2 aortic valves (Medtronic's CoreValve and the Edwards SAPIEN valve), which can be implanted using catheters, have been developed. In observational studies, the success rate for transcatheter aortic valve implantation has been greater than $95 \%$, but the 30-day mortality ranged from $6 \%$ to $13 \%$. In addition, up to $39 \%$ of patients required a permanent pacemaker, up to $28 \%$ of patients experienced major vascular complications, and up to $42 \%$ developed moderate to severe AS. The case series data and the comparative studies gave inadequate information to fully understand the relative benefits and harms of TAVR compared with standard surgical valve replacement.

The PARTNER A trial is the pivotal randomized trial that helps us understand the balance of risks and harms of TAVR compared with SAVR. ${ }^{38-42}$ In the trial, 348 patients with severe AS were randomized to the TAVR group (Edwards SAPIEN valve via the transfemoral or transapical approach) and 351 patients were randomized to the surgical therapy group. Mortality over 2 years 
was virtually identical at $35 \%$ and there was no excess of stroke, pacemaker placement, valve failure, or rehospitalization in the TAVR group. Quality of life measures improved faster in the TAVR group but were essentially the same in the 2 groups by 6 months. The excess of major vascular complications in the TAVR group was balanced by an excess of major bleeding episodes in the surgical group. Other features that weigh in favor of TAVR include avoiding a median sternotomy, a shorter stay in the ICU, and a shorter hospitalization. The major remaining concern is the excess of paravalvular aortic regurgitation in the TAVR group compared with the surgical group.

The trial was not methodologically perfect. Forty-two patients were not treated as randomized and all but 4 of them were in the surgical group. This may have introduced some selection bias because it represents more than $10 \%$ of the patients randomized to the surgical group. In addition, the time from randomization to procedure was significantly longer in the surgical group. This may in part explain why 10 patients randomized to the surgical group died before their procedure whereas only 3 patients in the TAVR group died before their procedure. Intention-to-treat analyses, per protocol analyses, and sensitivity analyses suggest that these problems are not large enough to invalidate the conclusion that the 2 treatments are equally beneficial, but others may judge differently.

Patient selection is essential to ensure that the results of the PARTNER trial apply to patients treated in the community. A multidisciplinary team that includes at a minimum 1 cardiac surgeon, a general cardiologist, and an interventional cardiologist should agree that a patient is high risk before offering TAVR. Patients must be informed of the upfront risks of death, stroke, pacemaker placement, and major vascular complications $(11 \%$ in the PARTNER A trial). Patients also need to be informed that some uncertainty remains about the durability of percutaneous aortic valves beyond 3 years. There is a high prevalence of moderate to severe aortic regurgitation, which may lead to recurrent symptoms or unforeseen problems with the valve. As was highlighted at the February 2012 CTAF meeting, the dispersion of this technology to new centers across the United States must proceed with careful thought given to training and proctoring multidisciplinary teams to become new centers of excellence. Attention needs to be paid to appropriate patient selection, their preoperative evaluation, surgical techniques, and postoperative care to preserve and improve on the results attained in the PARTNER trial. As described under TA Criterion 5, the specialty societies are collaborating to ensure that this happens in a rational and comprehensive manner. ${ }^{116}$

\section{References}

1. Wendler O, Walther T, Schroefel H, et al. Transapical aortic valve implantation: mid-term outcome from the SOURCE registry. Eur J Cardiothorac Surg. 2012; 43:505-11.

2. Sinning JM, Horack M, Grube E, et al. The impact of peripheral arterial disease on early outcome after transcatheter aortic valve implantation: results from the German Transcatheter Aortic Valve Interventions Registry. Am Heart J. 2012; 164:102-10.e1.

3. Lauten A, Zahn R, Horack M, et al. Transcatheter aortic valve implantation in patients with low-flow, low-gradient aortic stenosis. JACC Cardiovasc Interv. 2012;5:552-9

4. Humphries KH, Toggweiler S, Rodes-Cabau J, et al. Sex differences in mortality after transcatheter aortic valve replacement for severe aortic stenosis. J Am Coll Cardiol. 2012;60:882-6.

5. Gilard M, Eltchaninoff H, Iung B, et al. Registry of transcatheter aortic-valve implantation in high-risk patients. $N$ Engl J Med. 2012;366:1705-15.

6. Genereux P, Head SJ, Van Mieghem NM, et al. Clinical outcomes after transcatheter aortic valve replacement using valve academic research consortium definitions: a weighted meta-analysis of 3,519 patients from 16 studies. J Am Coll Cardiol. 2012;59:2317-26.

7. Eggebrecht H, Schmermund A, Voigtlander T, Kahlert P, Erbel R, Mehta RH Risk of stroke after transcatheter aortic valve implantation (TAVI) a meta-analysis of 10,037 published patients. EuroIntervention. 2012;8:129-38.

8. D’Onofrio A, Rubino P, Fusari M, et al. Impact of previous cardiac operations on patients undergoing transapical aortic valve implantation: results from the Italian Registry of Transapical Aortic Valve Implantation. Eur J Cardiothorac Surg. 2012;42:480-5.

9. Buellesfeld L, Gerckens U, Erbel R, et al. Age-stratified baseline and outcome characteristics of patients undergoing transcatheter aortic valve implantation: results from the German multicenter registry. J Invasive Cardiol. 2012;24: $531-6$.

10. Zahn R, Gerckens U, Grube E, et al. Transcatheter aortic valve implantation: first results from a multi-centre real-world registry. Eur Heart J. 2011;32: 198-204.

11. Wendler O, Walther T, Schroefel H, et al. The SOURCE Registry: what is the learning curve in trans-apical aortic valve implantation? Eur J Cardiothorac Surg. 2011;39:853-9; discussion 859-60.

12. Thomas M, Schymik G, Walther T, et al. One-year outcomes of cohort 1 in the Edwards SAPIEN Aortic Bioprosthesis European Outcome (SOURCE) registry: the European registry of transcatheter aortic valve implantation using the Edwards SAPIEN valve. Circulation. 2011;124:425-33.

13. Tamburino C, Capodanno D, Ramondo A, et al. Incidence and predictors of early and late mortality after transcatheter aortic valve implantation in 663 patients with severe aortic stenosis. Circulation. 2011;123:299-308.

14. Moat NE, Ludman P, de Belder MA, et al. Long-term outcomes after transcatheter aortic valve implantation in high-risk patients with severe aortic stenosis: the U.K. TAVI (United Kingdom Transcatheter Aortic Valve Implantation) Registry. J Am Coll Cardiol. 2011;58:2130-8.

15. Lefevre T, Kappetein AP, Wolner E, et al. One year follow-up of the multi-centre European PARTNER transcatheter heart valve study Eur Heart J. 2011;32:148-57.

16. Gurvitch R, Toggweiler S, Willson AB, et al. Outcomes and complications of transcatheter aortic valve replacement using a balloon expandable valve according to the Valve Academic Research Consortium (VARC) guidelines. EuroIntervention. 2011;7:41-8.

17. Gurvitch R, Tay EL, Wijesinghe N, et al. Transcatheter aortic valve implantation: lessons from the learning curve of the first 270 high-risk patients. Catheter Cardiovasc Interv. 2011;78:977-84.

18. Eltchaninoff H, Prat A, Gilard M, et al. Transcatheter aortic valve implantation: early results of the FRANCE (FRench Aortic National CoreValve and Edwards) registry. Eur Heart J. 2011;32:191-7.

19. D'Onofrio A, Rubino P, Fusari M, et al. Clinical and hemodynamic outcomes of "all-comers" undergoing transapical aortic valve implantation: results from the Italian Registry of Trans-Apical Aortic Valve Implantation (I-TA). J Thorac Cardiovasc Surg. 2011;142:768-75.

20. Bosmans JM, Kefer J, De Bruyne B, et al. Procedural, 30-day and one year outcome following CoreValve or Edwards transcatheter aortic valve implantation: results of the Belgian national registry. Interact Cardiovasc Thorac Surg. 2011;12:762-7. 
21. Abdel-Wahab M, Zahn R, Horack M, et al. Aortic regurgitation after transcatheter aortic valve implantation: incidence and early outcome. Results from the German transcatheter aortic valve interventions registry. Heart. 2011;97:899-906.

22. Wendler $\mathrm{O}$, Walther $\mathrm{T}$, Nataf $\mathrm{P}$, et al. Trans-apical aortic valve implantation: univariate and multivariate analyses of the early results from the SOURCE registry. Eur J Cardiothorac Surg. 2010;38:119-27.

23. Thomas M, Schymik G, Walther T, et al. Thirty-day results of the SAPIEN aortic Bioprosthesis European Outcome (SOURCE) Registry: a European registry of transcatheter aortic valve implantation using the Edwards SAPIEN valve. Circulation. 2010;122:62-9.

24. Rodes-Cabau J, Webb JG, Cheung A, et al. Transcatheter aortic valve implantation for the treatment of severe symptomatic aortic stenosis in patients at very high or prohibitive surgical risk: acute and late outcomes of the multicenter Canadian experience. J Am Coll Cardiol. 2010;55:1080-90.

25. Webb JG, Altwegg L, Boone RH, et al. Transcatheter aortic valve implantation: impact on clinical and valve-related outcomes. Circulation. 2009;119:3009-16.

26. Piazza N, Grube E, Gerckens U, et al. Procedural and 30-day outcomes following transcatheter aortic valve implantation using the third generation (18 Fr) corevalve revalving system: results from the multicentre, expanded evaluation registry 1-year following CE mark approval. EuroIntervention. 2008;4:242-9.

27. Grube E, Buellesfeld L, Mueller R, et al. Progress and current status of percutaneous aortic valve replacement: results of three device generations of the CoreValve Revalving system. Circ Cardiovasc Interv. 2008;1:167-75.

28. Ben-Dor I, Dvir D, Barbash IM, et al. Outcomes of patients with severe aortic stenosis at high surgical risk evaluated in a trial of transcatheter aortic valve implantation. Am J Cardiol. 2012;110:1008-14.

29. Clavel MA, Webb JG, Rodes-Cabau J, et al. Comparison between transcatheter and surgical prosthetic valve implantation in patients with severe aortic stenosis and reduced left ventricular ejection fraction. Circulation. 2010;122: 1928-36.

30. Conradi L, Seiffert M, Treede H, et al. Transcatheter aortic valve implantation versus surgical aortic valve replacement: a propensity score analysis in patients at high surgical risk. J Thorac Cardiovasc Surg. 2012;143:64-71.

31. Fusari M, Bona V, Muratori M, et al. Transcatheter vs. surgical aortic valve replacement: a retrospective analysis assessing clinical effectiveness and safety. J Cardiovasc Med (Hagerstown). 2012;13:229-41.

32. Higgins J, Ye J, Humphries KH, et al. Early clinical outcomes after transapical aortic valve implantation: a propensity-matched comparison with conventional aortic valve replacement. J Thorac Cardiovasc Surg. 2011;142:e47-52.

33. Jilaihawi H, Chakravarty T, Weiss RE, Fontana GP, Forrester J, Makkar RR. Meta-analysis of complications in aortic valve replacement: comparison of Medtronic-Corevalve, Edwards-Sapien and surgical aortic valve replacement in 8,536 patients. Catheter Cardiovasc Interv. 2012;80:128-38.

34. Piazza N, van Gameren M, Juni P, et al. A comparison of patient characteristics and 30-day mortality outcomes after transcatheter aortic valve implantation and surgical aortic valve replacement for the treatment of aortic stenosis: a two-centre study. EuroIntervention. 2009;5:580-8.

35. Stohr R, Dohmen G, Herpertz R, et al. Thirty-day outcome after transcatheter aortic valve implantation compared with surgical valve replacement in patients with high-risk aortic stenosis: a matched comparison. Coron Artery Dis. 2011; 22:595-600.

36. Walther T, Schuler G, Borger MA, et al. Transapical aortic valve implantation in 100 consecutive patients: comparison to propensity-matched conventional aortic valve replacement. Eur Heart J. 2010;31:1398-403.

37. Zierer A, Wimmer-Greinecker G, Martens S, Moritz A, Doss M. Is transapical aortic valve implantation really less invasive than minimally invasive aortic valve replacement? J Thorac Cardiovasc Surg. 2009;138:1067-72.

38. Genereux P, Webb JG, Svensson LG, et al. Vascular complications after transcatheter aortic valve replacement: insights from the PARTNER (Placement of AoRTic TraNscathetER Valve) trial. J Am Coll Cardiol. 2012;60: $1043-52$.

39. Kodali SK, Williams MR, Smith CR, et al. Two-year outcomes after transcatheter or surgical aortic-valve replacement. N Engl J Med. 2012;366: 1686-95.

40. Miller DC, Blackstone EH, Mack MJ, et al. Transcatheter (TAVR) versus surgical (AVR) aortic valve replacement: occurrence, hazard, risk factors, and consequences of neurologic events in the PARTNER trial. J Thorac Cardiovasc Surg. 2012;143:832-43.e13.
41. Reynolds MR, Magnuson EA, Wang K, et al. Health-related quality of life after transcatheter or surgical aortic valve replacement in high-risk patients with severe aortic stenosis: results from the PARTNER (Placement of AoRTic TraNscathetER Valve) Trial (Cohort A). J Am Coll Cardiol. 2012;60: 548-58.

42. Smith CR, Leon MB, Mack MJ, et al. Transcatheter versus surgical aortic-valve replacement in high-risk patients. N Engl J Med. 2011;364:2187-98.

43. Abdel-Wahab M, Zahn R, Horack M, et al. Transcatheter aortic valve implantation in patients with and without concomitant coronary artery disease: comparison of characteristics and early outcome in the German multicenter TAVI registry. Clin Res Cardiol. 2012;101:973-81.

44. Al-Attar N, Himbert D, Descoutures F, et al. Transcatheter aortic valve implantation: selection strategy is crucial for outcome. Ann Thorac Surg. 2009;87:1757-62; discussion 62-3.

45. Bauer F, Eltchaninoff $\mathrm{H}$, Tron $\mathrm{C}$, et al. Acute improvement in global and regional left ventricular systolic function after percutaneous heart valve implantation in patients with symptomatic aortic stenosis. Circulation. 2004; 110:1473-6.

46. Bauer F, Lemercier M, Zajarias A, Tron C, Eltchaninoff H, Cribier A Immediate and long-term echocardiographic findings after transcatheter aortic valve implantation for the treatment of aortic stenosis: the Cribier-Edwards/ Edwards-Sapien valve experience. J Am Soc Echocardiogr. 2010;23:370-6.

47. Behan M, Haworth P, Hutchinson N, Trivedi U, Laborde JC, Hildick-Smith D Percutaneous aortic valve implants under sedation: our initial experience. Catheter Cardiovasc Interv. 2008;72:1012-5.

48. Berry C, Asgar A, Lamarche Y, et al. Novel therapeutic aspects of percutaneous aortic valve replacement with the $21 \mathrm{~F}$ CoreValve Revalving System. Catheter Cardiovasc Interv. 2007;70:610-6.

49. Berry C, Oukerraj L, Asgar A, et al. Role of transesophageal echocardiography in percutaneous aortic valve replacement with the CoreValve Revalving system. Echocardiography. 2008;25:840-8.

50. Bleiziffer S, Mazzitelli D, Opitz A, et al. Beyond the short-term: clinical outcome and valve performance 2 years after transcatheter aortic valve implantation in 227 patients. J Thorac Cardiovasc Surg. 2012;143:310-7.

51. Buellesfeld L, Gerckens U, Schuler G, et al. 2-year follow-up of patients undergoing transcatheter aortic valve implantation using a self-expanding valve prosthesis. J Am Coll Cardiol. 2011;57:1650-7.

52. Chandavimol M, McClure SJ, Carere RG, et al. Percutaneous aortic valve implantation: a case report. Can J Cardiol. 2006;22:1159-61.

53. Chieffo A, Buchanan GL, Van Mieghem NM, et al. Transcatheter aortic valve implantation with the Edwards SAPIEN versus the Medtronic CoreValve revalving system devices: a multicenter collaborative study. The PRAGMATIC Plus Initiative (Pooled-RotterdAm-Milano-Toulouse In Collaboration), J Am Coll Cardiol. 2013;61:830-6.

54. Cribier A, Eltchaninoff $\mathrm{H}$, Bash A, et al. Percutaneous transcatheter implantation of an aortic valve prosthesis for calcific aortic stenosis: first human case description. Circulation. 2002;106:3006-8.

55. Cribier A, Eltchaninoff H, Tron C, et al. Treatment of calcific aortic stenosis with the percutaneous heart valve: mid-term follow-up from the initial feasibility studies: the French experience. J Am Coll Cardiol. 2006;47: 1214-23.

56. Cribier A, Eltchaninoff H, Tron C, et al. Early experience with percutaneous transcatheter implantation of heart valve prosthesis for the treatment of end-stage inoperable patients with calcific aortic stenosis. J Am Coll Cardiol. 2004;43:698-703.

57. Dager AE, Nuis RJ, Caicedo B, et al. Colombian experience with transcatheter aortic valve implantation of medtronic CoreValve. Tex Heart Inst J. 2012;39: $351-8$.

58. De Jaegere PP, Piazza N, Galema TW, et al. Early echocardiographic evaluation following percutaneous implantation with the self-expanding CoreValve Revalving System aortic valve bioprosthesis. EuroIntervention. 2008;4:351-7.

59. Descoutures F, Himbert D, Lepage L, et al. Contemporary surgical or percutaneous management of severe aortic stenosis in the elderly. Eur Heart J. 2008;29:1410-7.

60. Durand E, Borz B, Godin M, et al. Transfemoral aortic valve replacement with the Edwards SAPIEN and Edwards SAPIEN XT prosthesis using exclusively local anesthesia and fluoroscopic guidance: feasibility and 30-day outcomes. JACC Cardiovasc Interv. 2012;5:461-7.

61. Eltchaninoff H, Tron C, Bauer F, et al. Aortic bioprosthesis implanted percutaneously: three year follow up [in French]. Arch Mal Coeur Vaiss. 2007; 100:901, 904-8. 
62. Eltchaninoff H, Zajarias A, Tron C, et al. Transcatheter aortic valve implantation: technical aspects, results and indications. Arch Cardiovasc Dis. 2008;101:126-32.

63. Gotzmann M, Bojara W, Lindstaedt M, et al. One-year results of transcatheter aortic valve implantation in severe symptomatic aortic valve stenosis. Am J Cardiol. 2011;107:1687-92.

64. Grube E, Laborde JC, Gerckens U, et al. Percutaneous implantation of the CoreValve self-expanding valve prosthesis in high-risk patients with aortic valve disease: the Siegburg first-in-man study. Circulation. 2006;114:1616-24.

65. Grube E, Laborde JC, Zickmann B, et al. First report on a human percutaneous transluminal implantation of a self-expanding valve prosthesis for interventional treatment of aortic valve stenosis. Catheter Cardiovasc Interv. 2005;66:465-9.

66. Grube E, Schuler G, Buellesfeld L, et al. Percutaneous aortic valve replacement for severe aortic stenosis in high-risk patients using the second- and current third-generation self-expanding CoreValve prosthesis: device success and 30-day clinical outcome. J Am Coll Cardiol. 2007;50:69-76.

67. Gurvitch R, Wood DA, Tay EL, et al. Transcatheter aortic valve implantation: durability of clinical and hemodynamic outcomes beyond 3 years in a large patient cohort. Circulation. 2010;122:1319-27.

68. Himbert D, Descoutures F, Al-Attar N, et al. Results of transfemoral or transapical aortic valve implantation following a uniform assessment in high-risk patients with aortic stenosis. J Am Coll Cardiol. 2009;54:303-11.

69. Kodali SK, O'Neill WW, Moses JW, et al. Early and late (one year) outcomes following transcatheter aortic valve implantation in patients with severe aortic stenosis (from the United States REVIVAL trial). Am J Cardiol. 2011;107: 1058-64.

70. Latib A, Ielasi A, Montorfano M, et al. Transcatheter valve-in-valve implantation with the Edwards SAPIEN in patients with bioprosthetic heart valve failure: the Milan experience. EuroIntervention. 2012;7:1275-84.

71. Lichtenstein SV, Cheung A, Ye J, et al. Transapical transcatheter aortic valve implantation in humans: initial clinical experience. Circulation. 2006;114: 591-6.

72. Litzler PY, Borz B, Smail H, et al. Transapical aortic valve implantation in Rouen: four years' experience with the Edwards transcatheter prosthesis. Arch Cardiovasc Dis. 2012;105:141-5.

73. Marcheix B, Lamarche Y, Berry C, et al. Surgical aspects of endovascular retrograde implantation of the aortic CoreValve bioprosthesis in high-risk older patients with severe symptomatic aortic stenosis. J Thorac Cardiovasc Surg. 2007; 134:1150-6.

74. Nielsen HH, Thuesen L, Egeblad H, et al. Single center experience with transcatheter aortic valve implantation using the Edwards SAPIEN Valve. Scand Cardiovasc J. 2011;45:261-6.

75. Osten MD, Feindel C, Greutmann M, et al. Transcatheter aortic valve implantation for high risk patients with severe aortic stenosis using the Edwards Sapien balloon-expandable bioprosthesis: a single centre study with immediate and medium-term outcomes. Catheter Cardiovasc Interv. 2010;75:475-85.

76. Otten AM, van Domburg RT, van Gameren M, et al. Population characteristics, treatment assignment and survival of patients with aortic stenosis referred for percutaneous valve replacement. EuroIntervention. 2008;4:250-5.

77. Ree RM, Bowering JB, Schwarz SK. Case series: anesthesia for retrograde percutaneous aortic valve replacement-experience with the first 40 patients. Can J Anaesth. 2008:55:761-8.

78. Rodes-Cabau J, Dumont E, De LaRochelliere R, et al. Feasibility and initial results of percutaneous aortic valve implantation including selection of the transfemoral or transapical approach in patients with severe aortic stenosis. Am J Cardiol. 2008;102:1240-6.

79. Spargias K, Manginas A, Pavlides G, et al. Transcatheter aortic valve implantation: first Greek experience. Hellenic J Cardiol. 2008;49:397-407.

80. Stahli BE, Bunzli R, Grunenfelder J, et al. Transcatheter aortic valve implantation (TAVI) outcome according to standardized endpoint definitions by the Valve Academic Research Consortium (VARC). J Invasive Cardiol. 2011;23:307-12.

81. Staubach S, Franke J, Gerckens U, et al. Impact of aortic valve calcification on the outcome of transcatheter aortic valve implantation: results from the prospective multicenter German TAVI registry. Catheter Cardiovasc Interv. 2012;81:348-55.

82. Stortecky S, Brinks H, Wenaweser P, et al. Transcatheter aortic valve implantation or surgical aortic valve replacement as redo procedure after prior coronary artery bypass grafting. Ann Thorac Surg. 2011;92:1324-30; discussion 230-1.
83. Subramanian S, Rastan AJ, Holzhey D, et al. Conventional aortic valve replacement in transcatheter aortic valve implantation candidates: a 5-year experience. Ann Thorac Surg. 2012;94:726-9; discussion 729-30.

84. Svensson LG, Dewey T, Kapadia S, et al. United States feasibility study of transcatheter insertion of a stented aortic valve by the left ventricular apex. Ann Thorac Surg. 2008;86:46-54; discussion 55.

85. Tamburino C, Barbanti M, Capodanno D, et al. Early- and mid-term outcomes of transcatheter aortic valve implantation in patients with logistic EuroSCORE less than 20\%: a comparative analysis between different risk strata. Catheter Cardiovasc Interv. 2012;79:132-40.

86. Tamburino C, Capodanno D, Mule M, et al. Procedural success and 30-day clinical outcomes after percutaneous aortic valve replacement using current third-generation self-expanding CoreValve prosthesis. J Invasive Cardiol. 2009;21:93-8.

87. Tchetche D, Dumonteil N, Sauguet A, et al. Thirty-day outcome and vascular complications after transarterial aortic valve implantation using both Edwards Sapien and Medtronic CoreValve bioprostheses in a mixed population. EuroIntervention. 2010;5:659-65.

88. Thielmann M, Wendt D, Eggebrecht $H$, et al. Transcatheter aortic valve implantation in patients with very high risk for conventional aortic valve replacement. Ann Thorac Surg. 2009;88:1468-74.

89. Ussia GP, Barbanti M, Cammalleri V, et al. Quality-of-life in elderly patients one year after transcatheter aortic valve implantation for severe aortic stenosis. EuroIntervention. 2011;7:573-9.

90. Ussia GP, Barbanti M, Petronio AS, et al. Transcatheter aortic valve implantation: 3-year outcomes of self-expanding CoreValve prosthesis. Eur Heart J. 2012;33:969-76.

91. Walther T, Falk V, Borger MA, et al. Minimally invasive transapical beating heart aortic valve implantation-proof of concept. Eur J Cardiothorac Surg. 2007;31:9-15.

92. Walther T, Falk V, Kempfert J, et al. Transapical minimally invasive aortic valve implantation; the initial 50 patients. Eur J Cardiothorac Surg. 2008;33:983-8.

93. Walther T, Kasimir MT, Doss M, et al. One-year interim follow-up results of the TRAVERCE trial: the initial feasibility study for trans-apical aortic-valve implantation. Eur J Cardiothorac Surg. 2011;39:532-7.

94. Walther T, Kempfert J, Rastan A, et al. Transapical aortic valve implantation at 3 years. J Thorac Cardiovasc Surg. 2012;143:326-31.

95. Van Linden A, Kempfert J, Blumenstein J, et al. Transapical aortic valve implantation off-pump in patients with impaired left ventricular function. Ann Thorac Surg. 2011;92:18-23.

96. Walther T, Simon P, Dewey T, et al. Transapical minimally invasive aortic valve implantation: multicenter experience. Circulation. 2007;116(11 Suppl):I240-5.

97. Walther T, Thielmann M, Kempfert J, et al. PREVAIL TRANSAPICAL: multicentre trial of transcatheter aortic valve implantation using the newly designed bioprosthesis (SAPIEN-XT) and delivery system (ASCENDRA-II). Eur J Cardiothorac Surg. 2012;42:278-83; discussion 83.

98. Walther T, Thielmann M, Kempfert J, et al. One-year multicentre outcomes of transapical aortic valve implantation using the SAPIEN XT valve: the PREVAIL transapical study. Eur J Cardiothorac Surg. 2013;43:986-92.

99. Webb JG, Chandavimol M, Thompson CR, et al. Percutaneous aortic valve implantation retrograde from the femoral artery. Circulation. 2006;113:842-50.

100. Webb JG, Pasupati S, Humphries K, et al. Percutaneous transarterial aortic valve replacement in selected high-risk patients with aortic stenosis. Circulation. 2007; 116:755-63.

101. Wendler O, Thielmann M, Schroefel H, et al. Worldwide experience with the 29-mm Edwards SAPIEN XTTM transcatheter heart valve in patients with large aortic annulus. Eur J Cardiothorac Surg. 2013;43:371-7.

102. Wijesinghe N, Ye J, Rodes-Cabau J, et al. Transcatheter aortic valve implantation in patients with bicuspid aortic valve stenosis. JACC Cardiovasc Interv. 2010;3:1122-5.

103. Ye J, Cheung A, Lichtenstein SV, et al. Transapical transcatheter aortic valve implantation: 1-year outcome in 26 patients. J Thorac Cardiovasc Surg. 2009; 137:167-73.

104. Ye J, Cheung A, Lichtenstein SV, et al. Transapical transcatheter aortic valve implantation: follow-up to 3 years. J Thorac Cardiovasc Surg. 2010;139: 1107-13, 1113.e1.

105. Ye J, Cheung A, Lichtenstein SV, et al. Six-month outcome of transapical transcatheter aortic valve implantation in the initial seven patients. Eur J Cardiothorac Surg. 2007;31:16-21.

106. Ye J, Webb JG, Cheung A, et al. Transcatheter valve-in-valve aortic valve implantation: 16-month follow-up. Ann Thorac Surg. 2009;88:1322-4. 
107. Zierer A, Wimmer-Greinecker G, Martens S, Moritz A, Doss M. The transapical approach for aortic valve implantation. J Thorac Cardiovasc Surg. 2008;136: 948-53.

108. The Ciriteria Committee of the New York Heart Association. Nomenclature and criteria for diagnosis of diseases of the heart and great vessels. 9th ed. Boston: Little, Brown; 1994.

109. Green CP, Porter CB, Bresnahan DR, Spertus JA. Development and evaluation of the Kansas City Cardiomyopathy Questionnaire: a new health status measure for heart failure. J Am Coll Cardiol. 2000;35:1245-55.

110. Soto GE, Jones P, Weintraub WS, Krumholz HM, Spertus JA. Prognostic value of health status in patients with heart failure after acute myocardial infarction. Circulation. 2004;110:546-51.

111. Leon MB, Piazza N, Nikolsky E, et al. Standardized endpoint definitions for Transcatheter Aortic Valve Implantation clinical trials: a consensus report from the Valve Academic Research Consortium. J Am Coll Cardiol. 2011;57: 253-69.
112. Tice JA, California Technology Assessment Forum. Transcatheter aortic valve replacement in patients with severe aortic stenosis who cannot undergo surgery. San Francisco, Calif: California Technology Assessment Forum; 2012.

113. Leon MB, Smith CR, Mack M, et al. Transcatheter aortic-valve implantation for aortic stenosis in patients who cannot undergo surgery. N Engl J Med. 2010;363: 1597-607.

114. Makkar RR, Fontana GP, Jilaihawi H, et al. Transcatheter aortic-valve replacement for inoperable severe aortic stenosis. N Engl J Med. 2012; 366:1696-704.

115. Reynolds MR, Magnuson EA, Lei Y, et al. Health-related quality of life after transcatheter aortic valve replacement in inoperable patients with severe aortic stenosis. Circulation. 2011;124:1964-72.

116. Holmes DR Jr, Mack MJ. Transcatheter valve therapy: a professional society overview from the American College of Cardiology Foundation and the Society of Thoracic Surgeons. J Am Coll Cardiol. 2011;58:445-55. 


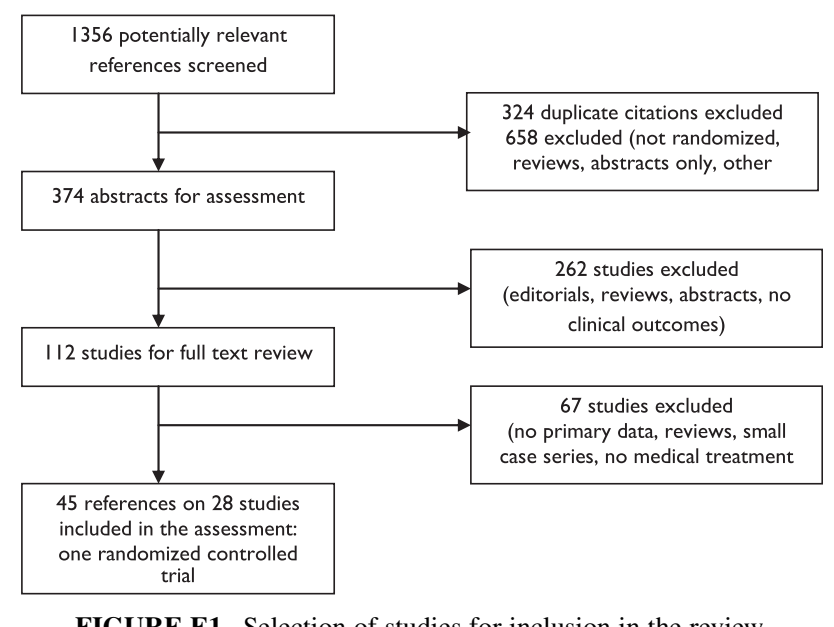

FIGURE E1. Selection of studies for inclusion in the review. 
TABLE E1. Characteristics of the larger published studies on transcatheter aortic valve replacement

\begin{tabular}{|c|c|c|c|c|c|c|c|c|c|c|}
\hline Study & Group & Location & $\mathbf{N}$ & Time frame & Valve type & $\begin{array}{c}\text { Follow-up } \\
\text { (months) }\end{array}$ & $\begin{array}{c}\text { Age } \\
\text { (years) }\end{array}$ & $\begin{array}{c}\text { Sex } \\
(\% \text { female })\end{array}$ & $\begin{array}{c}\text { Log } \\
\text { EuroSCORE }\end{array}$ & $\begin{array}{c}\text { STS } \\
\text { score }\end{array}$ \\
\hline \multicolumn{11}{|l|}{ Uncontrolled cohorts } \\
\hline Grube 2008 & TAVR & Sieborg, Germany & 136 & $2005-2008$ & CoreValve & NR & 82 & 58 & 23 & 9 \\
\hline Piazza 2008 & TAVR & Multicenter & 646 & $2007-2008$ & CoreValve & NR & 81 & & 23 & NR \\
\hline Rodes-Cabeau 2010 & TAVR & Canada, 6 centers & 339 & $2005-2009$ & SAPIEN & 8 & 81 & 55 & NR & 10 \\
\hline Bosmans 2011 & TAVR & Multicenter Belgium & 328 & $?-2010$ & $\begin{array}{r}\text { CoreValve, } \\
\text { SAPIEN }\end{array}$ & NR & 83 & 54 & 28 & NR \\
\hline D'Onofrio 2011, 2012 & TAVR & Multicenter Italy & 566 & 2008-2011 & SAPIEN & 10 & 81 & 61 & 26 & 12 \\
\hline Eltchaninoff 2011 & TAVR & Multicenter France & 244 & 2009 & $\begin{array}{r}\text { CoreValve, } \\
\text { SAPIEN }\end{array}$ & 1 & 82 & 43 & 26 & 19 \\
\hline Gurvitch 2011 & TAVR & Vancouver, Canada & 270 & NR & SAPIEN & 1 & 83 & 50 & NR & 10 \\
\hline $\begin{array}{l}\text { Humphries 2011; } \\
\text { Webb } 2009\end{array}$ & TAVR & $\begin{array}{l}\text { Vancouver and } \\
\text { Quebec, Canada }\end{array}$ & 641 & $2005-2011$ & $\begin{array}{r}\text { CoreValve, } \\
\text { SAPIEN }\end{array}$ & 10 & 83 & 51 & NR & 8 \\
\hline \multirow[t]{2}{*}{ Lefevre 2011} & TAVR TF & Multicenter & 61 & 2007-2008 & SAPIEN & 12 & 82 & 61 & 26 & 11 \\
\hline & TAVR TA & Europe & 69 & & & & 82 & 51 & 34 & 12 \\
\hline Moat 2011 & TAVR & Multicenter UK & 870 & $2007-2009$ & $\begin{array}{r}\text { CoreValve, } \\
\text { SAPIEN }\end{array}$ & NR & 82 & 48 & 19 & NR \\
\hline Tamburino 2011 & TAVR & Multicenter Italy & 663 & 2007-2009 & CoreValve & 18 & 81 & 56 & 23 & NR \\
\hline \multirow[t]{2}{*}{ Thomas 2010, 2011} & TAVR TF & Multicenter Europe & 463 & $2007-2009$ & SAPIEN & 12 & 82 & 55 & 26 & NR \\
\hline & TAVR TA & & 575 & & & & 81 & 56 & 29 & \\
\hline Zahn 2011 & TAVR & Multicenter Germany & 697 & 2009 & $\begin{array}{r}\text { CoreValve, } \\
\text { SAPIEN }\end{array}$ & 1 & 81 & 56 & 21 & NR \\
\hline Eggebrecht 2012 & TAVR & MA 53 studies & 10,037 & 2004-2011 & $\begin{array}{r}\text { CoreValve, } \\
\text { SAPIEN }\end{array}$ & 1 & 82 & 53 & 25 & NR \\
\hline Genereux 2012 & TAVR & MA 16 studies & 3519 & $2008-2010$ & $\begin{array}{r}\text { CoreValve, } \\
\text { SAPIEN }\end{array}$ & 12 & NR & NR & 23 & 9 \\
\hline Gilard 2012 & TAVR & Multicenter France & 3195 & 2010-2011 & $\begin{array}{r}\text { CoreValve, } \\
\text { SAPIEN }\end{array}$ & 12 & 83 & 49 & 22 & 14 \\
\hline \multicolumn{11}{|l|}{ Comparative studies } \\
\hline \multirow[t]{2}{*}{ Kapadia 2009} & TAVR & Cleveland, Ohio & 18 & $2006-2007$ & SAPIEN & 9 & 81 & 33 & 28 & 11 \\
\hline & Medical & & 36 & & & 6 & 83 & 53 & 25 & 13 \\
\hline \multirow[t]{2}{*}{ Rajani 2010} & TAVR & Brighton, UK & 38 & $2007-2009$ & CoreValve & 7 & 83 & 45 & 24 & NR \\
\hline & Medical & & 47 & & & & 81 & 52 & 13 & NR \\
\hline \multirow[t]{2}{*}{ Piazza 2009} & TAVR & 2 European centers & 114 & 2006-2008 & & 1 & & & & \\
\hline & Surgical & & 1008 & & & & & & & \\
\hline \multirow[t]{2}{*}{ Zierer 2009} & TAVR & Frankfurt, Germany & 21 & $2006-2007$ & SAPIEN & 12 & 85 & 71 & 38 & NR \\
\hline & Surgical & & 30 & & & & 82 & 63 & 35 & NR \\
\hline \multirow[t]{2}{*}{ Clavel 2010} & TAVR & $\begin{array}{l}\text { Multicenter Canada, } \\
\text { Austria }\end{array}$ & 83 & $2006-2008$ & SAPIEN & 12 & 81 & 41 & 32 & 12 \\
\hline & Surgical & Germany & 200 & & & & 70 & 19 & 18 & 6 \\
\hline \multirow[t]{2}{*}{ Walther 2010} & TAVR & Leipzig, Germany & 100 & 2006-2008 & SAPIEN & 12 & 83 & 77 & 29 & 15 \\
\hline & Surgical & & 100 & 1996-2008 & & & 82 & 70 & 30 & NA \\
\hline \multirow[t]{2}{*}{ Higgins 2011} & TAVR & British Columbia, & 46 & 2005-2010 & SAPIEN & 1 & 78 & 80 & NR & NR \\
\hline & Surgical & Canada & 46 & 2001-2009 & & & 78 & 79 & NR & NR \\
\hline \multirow[t]{2}{*}{ Stohr 2011} & TAVR & Aachen, Germany & 175 & $2008-2010$ & CoreValve, & 1 & 80 & 40 & 21 & NR \\
\hline & Surgical & & 175 & & SAPIEN & & 79 & 24 & 17 & NR \\
\hline \multirow[t]{3}{*}{ Ben-Dor 2012} & TAVR & PARTNER & 159 & $2007-2011$ & SAPIEN & 13 & 84 & 57 & 42 & 12 \\
\hline & Surgical & nonrandomized & 146 & & & 24 & 79 & 49 & 27 & 8 \\
\hline & Medical & & 595 & & & 7 & 82 & 55 & 43 & 12 \\
\hline \multirow[t]{2}{*}{ Conradi 2012} & TAVR & Hamburg, Germany & 82 & 2009-2010 & SAPIEN & 6 & 82 & 63 & 24 & 9 \\
\hline & Surgical & & 82 & & & & 82 & 58 & 24 & 9 \\
\hline \multirow[t]{2}{*}{ Fusari 2012} & TAVR & Italy & 106 & 2008-2009 & SAPIEN & 21 & 81 & 68 & 22 & 8.4 \\
\hline & Surgical & & 81 & & & 22 & 78 & 67 & 8.5 & 2.8 \\
\hline \multirow[t]{2}{*}{ Jilaihawi 2012} & TAVR & MA 35 studies & 5024 & Before 2010 & CoreValve, & 24 & 81 & 54 & 25 & NR \\
\hline & Surgical & & 3512 & & SAPIEN & & 82 & 56 & 18 & NR \\
\hline
\end{tabular}


TABLE E1. Continued

\begin{tabular}{|c|c|c|c|c|c|c|c|c|c|c|}
\hline Study & Group & Location & $\mathbf{N}$ & Time frame & Valve type & $\begin{array}{c}\text { Follow-up } \\
\text { (months) }\end{array}$ & $\begin{array}{c}\text { Age } \\
\text { (years) }\end{array}$ & $\begin{array}{c}\text { Sex } \\
(\% \text { female })\end{array}$ & $\begin{array}{c}\log \\
\text { EuroSCORE }\end{array}$ & $\begin{array}{l}\text { STS } \\
\text { score }\end{array}$ \\
\hline \multicolumn{11}{|l|}{ Randomized trials } \\
\hline $\begin{array}{l}\text { PARTNER B } \\
\quad \text { (inoperable) }\end{array}$ & TAVR & $\begin{array}{l}\text { Multicenter, } \\
\text { United States, } \\
\text { Germany, Canada }\end{array}$ & 179 & $2007-2009$ & SAPIEN & 19 & 83 & 54 & 28 & 12 \\
\hline Leon 2010 & Medical & & 179 & & & & & & & \\
\hline $\begin{array}{c}\text { PARTNER A } \\
\text { (high risk) }\end{array}$ & TAVR & $\begin{array}{l}\text { Multicenter, } \\
\text { United States, } \\
\text { Germany, Canada }\end{array}$ & 348 & $2007-2009$ & SAPIEN & 24 & 84 & 43 & 29 & 12 \\
\hline $\begin{array}{l}\text { Smith } 2011 \\
\text { Kodali } 2012\end{array}$ & Surgical & & 351 & & & & & & & \\
\hline
\end{tabular}

$T A V R$, Transcatheter aortic valve replacement; $N R$, not reported; $T F$, transfemoral; TA, transapical; NA, not available; STS, Society of Thoracic Surgeons; EuroSCORE, European System for Cardiac Operative Risk Evaluation; MA, meta-analysis; PARTNER, Placement of Aortic Transcatheter Valve Trial. 
TABLE E2. Procedural and 30-day benefits and harms of transcatheter aortic valve replacement

\begin{tabular}{|c|c|c|c|c|c|c|c|c|c|c|c|}
\hline Study & Group & $\begin{array}{c}\text { Procedural } \\
\text { success } \\
(\%) \\
\end{array}$ & $\begin{array}{c}\text { Death } \\
(\%) \\
\end{array}$ & $\begin{array}{c}\text { Major } \\
\text { stroke } \\
(\%) \\
\end{array}$ & $\begin{array}{c}\text { Major } \\
\text { vascular } \\
\text { complication }\end{array}$ & $\begin{array}{r}\text { Pacemaker } \\
\text { placement } \\
(\%) \\
\end{array}$ & $\begin{array}{c}\text { Moderate to } \\
\text { severe aortic } \\
\text { regurgitation } \\
(\%) \\
\end{array}$ & MI \% & $\begin{array}{c}\text { Tamponade } \\
(\%)\end{array}$ & $\begin{array}{c}\text { Major } \\
\text { bleeding } \\
(\%) \\
\end{array}$ & $\begin{array}{c}\begin{array}{c}\text { Need for } \\
\text { hemodialysi } \\
(\%)\end{array} \\
\end{array}$ \\
\hline \multicolumn{12}{|c|}{ Uncontrolled cohorts } \\
\hline Grube 2008 & TAVR & 86 & 12 & 1 & NR & 25 & 26 & 2 & 1 & NR & NR \\
\hline Piazza 2008 & TAVR & 97 & 8 & 2 & 2 & 9 & NR & 1 & 1 & 0 & NR \\
\hline $\begin{array}{l}\text { Rodes-Cabeau } \\
2010\end{array}$ & TAVR & 93 & 10 & 2 & 13 & 5 & 6 & 1 & 0 & $\mathrm{NR},>1.4$ & 3 \\
\hline Bosmans 2011 & TAVR & 97 & 11 & 5 & NR & NR & NR & NR & NR & NR & NR \\
\hline $\begin{array}{l}\text { D'Onofrio 2011, } \\
2012\end{array}$ & TAVR & 99 & 8 & 3 & NR & 5 & NR & 2 & NR & NR & 6 \\
\hline Eltchaninoff 2011 & TAVR & 98 & 13 & 4 & 7 & 12 & & & 2 & NR & 2 \\
\hline Gurvitch 2011 & TAVR & 95 & 10 & 3 & 7 & 6 & NR & NR & 2 & 9 & 3 \\
\hline Humphries 2011; & TAVR & $\begin{array}{l}\text { Failures } \\
\text { excluded }\end{array}$ & 9 & 2 & 9 & 6 & NR & NR & NR & 17 & NR \\
\hline \multicolumn{12}{|l|}{ Webb 2009} \\
\hline \multirow[t]{2}{*}{ Lefevre 2011} & TAVR TF & 96 & 8 & 3 & 28 & 2 & NR & 3 & NR & 5 & 0 \\
\hline & TAVR TA & 95 & 19 & 2 & 5 & 4 & & 6 & & 12 & 6 \\
\hline Moat 2011 & TAVR & 97 & 7 & 4 & 6 & 16 & 14 & 1 & NR & NR & NR \\
\hline Tamburino 2011 & TAVR & 98 & 6 & 1 & 2 & 17 & 21 & 0 & 1 & 3 & NR \\
\hline \multirow{2}{*}{$\begin{array}{l}\text { Thomas 2010, } \\
2011\end{array}$} & TAVR TF & 95 & 6 & 2 & 11 & 7 & 2 & NR & NR & NR & 1 \\
\hline & TAVR TA & 93 & 10 & 3 & 2 & 7 & 2 & & & & 7 \\
\hline Zahn 2011 & TAVR & 98 & 12 & 3 & 17 & 39 & Severe 2.3 & 1 & 2 & NR & NR \\
\hline Eggebrecht 2012 & TAVR & NR & 8 & 3 & NR & NR & NR & NR & NR & NR & NR \\
\hline Genereux 2012 & TAVR & 92 & 8 & 4 & 12 & 14 & 7 & 1 & 3 & 16 & NR \\
\hline Gilard 2012 & TAVR & 97 & 10 & 2 & 5 & 16 & 17 & NR & NR & 4 & NR \\
\hline \multicolumn{12}{|c|}{ Comparative studies } \\
\hline \multirow[t]{2}{*}{ Kapadia 2009} & TAVR & NR & 5 & 0 & NR & 6 & NR & 0 & NR & NR & NR \\
\hline & Medical & NR & NR & NR & NR & NR & NR & NR & NR & NR & NR \\
\hline \multirow[t]{2}{*}{ Rajani 2010} & TAVR & NR & 8 & 3 & 3 & 34 & NR & NR & 3 & NR & 3 \\
\hline & Medical & NR & NR & NR & NR & NR & NR & NR & NR & NR & NR \\
\hline \multirow[t]{2}{*}{ Piazza 2009} & TAVR & & 10 & & & & & & & & \\
\hline & Surgical & & 2 & & & & & & & & \\
\hline \multirow[t]{2}{*}{ Zierer 2009} & TAVR & 85 & 14 & 0 & NR & 0 & NR & NR & NR & NR & 0 \\
\hline & Surgical & 100 & 10 & 3 & NR & 3 & NR & NR & NR & NR & 10 \\
\hline \multirow[t]{2}{*}{ Clavel 2010} & TAVR & NR & 19 & NR & NR & NR & 6 & NR & NR & NR & NR \\
\hline & Surgical & NR & 12 & NR & NR & NR & 0 & NR & NR & NR & NR \\
\hline \multirow[t]{2}{*}{ Walther 2010} & TAVR & 97 & 10 & 0 & NR & 10 & NR & NR & NR & NR & NR \\
\hline & Surgical & 100 & 15 & 2 & NR & NR & NR & NR & NR & NR & NR \\
\hline \multirow[t]{2}{*}{ Higgins 2011} & TAVR & NR & 13 & 0 & NR & NR & NR & NR & NR & NR & NR \\
\hline & Surgical & NR & 9 & 4 & NR & NR & NR & NR & NR & NR & NR \\
\hline \multirow[t]{2}{*}{ Stohr 2011} & TAVR & 100 & 12 & 1 & NR & 15 & 3 & NR & NR & NR & 4 \\
\hline & Surgical & 100 & 8 & 0.5 & NR & 2 & 0 & NR & NR & NR & 14 \\
\hline \multirow[t]{3}{*}{ Ben-Dor 2012} & TAVR & NR & 12 & NR & NR & NR & NR & NR & NR & NR & NR \\
\hline & Surgical & NR & 13 & NR & NR & NR & NR & NR & NR & NR & NR \\
\hline & Medical & NR & 10 & NR & NR & NR & NR & NR & NR & NR & NR \\
\hline \multirow[t]{2}{*}{ Conradi 2012} & TAVR & 96 & 7 & 2 & NR & 4 & 1 & NR & NR & NR & NR \\
\hline & Surgical & 100 & 9 & 2 & NR & 2 & 0 & NR & NR & NR & NR \\
\hline \multirow[t]{2}{*}{ Fusari 2012} & TAVR & 100 & 2 & 1 & 4 & 6 & NR & 1 & 1 & 2 & 5 \\
\hline & Surgical & 100 & 4 & 2 & 0 & 1 & NR & 1 & 0 & 5 & 5 \\
\hline \multirow[t]{2}{*}{ Jilaihawi 2012} & TAVR & NR & 8 & 3 & 7 & 12 & 12 & 1 & 1 & NR & 4 \\
\hline & Surgical & $\mathrm{NR}$ & 9 & 2 & NR & 6 & NR & NR & NR & NR & 2 \\
\hline
\end{tabular}


TABLE E2. Continued

\begin{tabular}{|c|c|c|c|c|c|c|c|c|c|c|c|}
\hline Study & Group & $\begin{array}{c}\text { Procedural } \\
\text { success } \\
(\%)\end{array}$ & $\begin{array}{c}\text { Death } \\
(\%)\end{array}$ & $\begin{array}{c}\text { Major } \\
\text { stroke } \\
(\%)\end{array}$ & $\begin{array}{c}\text { Major } \\
\text { vascular } \\
\text { complication }\end{array}$ & $\begin{array}{c}\text { Pacemaker } \\
\text { placement } \\
(\%)\end{array}$ & $\begin{array}{c}\text { Moderate to } \\
\text { severe aortic } \\
\text { regurgitation } \\
(\%)\end{array}$ & MI \% & $\begin{array}{c}\text { Tamponade } \\
(\%)\end{array}$ & $\begin{array}{c}\text { Major } \\
\text { bleeding } \\
(\%)\end{array}$ & $\begin{array}{c}\text { Need for } \\
\text { hemodialysis } \\
(\%)\end{array}$ \\
\hline \multicolumn{12}{|l|}{ Randomized trials } \\
\hline PARTNER B & TAVR & 97 & 5 & 5 & 16 & 3 & 12 & 0 & NR & 17 & 1 \\
\hline Leon 2010 & Medical & 100 & 3 & 1 & 1 & 5 & - & 0 & NR & 4 & 2 \\
\hline PARTNER A & TAVR & 95 & 3.4 & 3.8 & 11.0 & 3.8 & 12.2 & 0 & NR & 9.3 & 2.9 \\
\hline Smith 2011 & Surgical & 99 & 6.5 & 2.1 & 3.2 & 3.6 & 0.9 & 0.6 & NR & 19.5 & 3.0 \\
\hline
\end{tabular}

$\overline{M I \text {, Myocardial infarction; TAVR, transcatheter aortic valve replacement; } N R \text {, not reported; } T F \text {, transfemoral; } T A \text {, transapical; PARTNER, Placement of Aortic Transcatheter Valve }}$ Trial. 
TABLE E3. Benefits and harms of transcatheter aortic valve replacement at 1 year

\begin{tabular}{|c|c|c|c|c|c|c|}
\hline Study & Group & Death & Major stroke & $\begin{array}{l}\text { NYHA heart } \\
\text { failure class }\end{array}$ & $\begin{array}{l}\text { Quality of } \\
\text { life KCCQ }\end{array}$ & $\begin{array}{l}\text { Quality of } \\
\text { life SF-12 }\end{array}$ \\
\hline \multicolumn{7}{|l|}{ Uncontrolled cohorts } \\
\hline Grube 2008 & TAVR & 18 & 4 & 3.3 to 1.7 & NR & NR \\
\hline Piazza 2008 & TAVR & NR & NR & NR & NR & NR \\
\hline Rodes-Cabeau 2010 & TAVR & 24 & NR & NR & NR & NR \\
\hline Bosmans 2011 & TAVR & 21 & NR & NR & NR & NR \\
\hline D’Onofrio 2011, 2012 & TAVR & 17 & NR & NR & NR & NR \\
\hline Eltchaninoff 2011 & TAVR & NR & NR & NR & NR & NR \\
\hline Gurvitch 2011 & TAVR & NR & NR & NR & NR & NR \\
\hline Humphries 2011; Webb 2009 & TAVR & $83 \mathrm{~F}, 73 \mathrm{M}$ & NR & NR & NR & NR \\
\hline \multirow[t]{2}{*}{ Lefevre 2011} & TAVR TF & 21 & 7 & $86 \%$ Class I or II & 50 to 68 & NR \\
\hline & TAVR TA & 51 & 10 & $80 \%$ Class I or II & 50 to 77 & \\
\hline Moat 2011 & TAVR & 21 & NR & NR & NR & NR \\
\hline Tamburino 2011 & TAVR & 15 & 3 & $>50 \%$ Class I or II & NR & NR \\
\hline \multirow[t]{2}{*}{ Thomas 2010, 2011} & TAVR TF & 19 & 5 & $78 \%$ Class I or II & NR & NR \\
\hline & TAVR TA & 28 & 5 & $69 \%$ Class I or II & & \\
\hline Zahn 2011 & TAVR & NR & NR & NR & NR & NR \\
\hline Eggebrecht 2012 & TAVR & NR & 5 & NR & NR & NR \\
\hline Genereux 2012 & TAVR & 22 & NR & NR & NR & NR \\
\hline Gilard 2012 & TAVR & 24 & 2 & $90 \%$ Class I or II & NR & NR \\
\hline \multicolumn{7}{|l|}{ Comparative studies } \\
\hline \multirow[t]{2}{*}{ Kapadia 2009} & TAVR & $\sim 22 \%$ & NR & NR & NR & NR \\
\hline & Medical & $\sim 44 \%$ & & & & \\
\hline \multirow[t]{2}{*}{ Rajani 2010} & TAVR & $\sim 13 \%$ & NR & NR & NR & NR \\
\hline & Medical & $\sim 28 \%$ & & & & \\
\hline \multirow[t]{2}{*}{ Piazza 2009} & TAVR & NR & NR & NR & NR & NR \\
\hline & Surgical & NR & NR & NR & NR & NR \\
\hline \multirow[t]{2}{*}{ Zierer 2009} & TAVR & 24 & NR & NR & NR & NR \\
\hline & Surgical & 17 & NR & NR & NR & NR \\
\hline \multirow[t]{2}{*}{ Clavel 2010} & TAVR & NR & NR & NR & NR & NR \\
\hline & Surgical & NR & NR & NR & NR & NR \\
\hline \multirow[t]{2}{*}{ Walther 2010} & TAVR & 27 & NR & NR & NR & NR \\
\hline & Surgical & 31 & NR & NR & NR & NR \\
\hline \multirow[t]{2}{*}{ Higgins 2011} & TAVR & NR & NR & NR & NR & NR \\
\hline & Surgical & NR & NR & NR & NR & NR \\
\hline \multirow[t]{2}{*}{ Stohr 2011} & TAVR & NR & NR & NR & NR & NR \\
\hline & Surgical & NR & NR & NR & NR & NR \\
\hline \multirow[t]{3}{*}{ Ben-Dor 2012} & TAVR & 21 & NR & NR & NR & NR \\
\hline & Surgical & 21 & NR & NR & NR & NR \\
\hline & Medical & 36 & NR & NR & NR & NR \\
\hline \multirow[t]{2}{*}{ Conradi 2012} & TAVR & NR & NR & NR & NR & NR \\
\hline & Surgical & NR & NR & NR & NR & NR \\
\hline \multirow[t]{2}{*}{ Fusari 2012} & TAVR & 12 & NR & $\sim 86 \%$ Class I or II & NR & NR \\
\hline & Surgical & 10 & NR & $\sim 84 \%$ Class I or II & NR & NR \\
\hline \multirow[t]{2}{*}{ Jilaihawi 2012} & TAVR & 23 & NR & NR & NR & NR \\
\hline & Surgical & 18 & NR & NR & NR & NR \\
\hline \multicolumn{7}{|l|}{ Randomized trials } \\
\hline PARTNER B & TAVR & 31 & 8 & $75 \%$ Class I or II & +32 & +7 \\
\hline Leon 2010 & Medical & 50 & 4 & $42 \%$ Class I or II & +4 & +2 \\
\hline \multicolumn{7}{|l|}{ Reynolds 2011} \\
\hline PARTNER A & TAVR & 24 & 5 & $\sim 63 \%$ Class I or II & +29 & +6.5 \\
\hline Smith 2011 & Surgical & 27 & 2 & $\sim 63 \%$ Class I or II & +25 & +5.6 \\
\hline Kodali 2012 & & & & & & \\
\hline
\end{tabular}

